\title{
Strategy for assessment of disaster risk using typhoon hazards modeling based on chlorophyll-a content of seawater
}

\author{
Di Wu ${ }^{1,2}$, Mengxing Huang ${ }^{1,2^{*}}$, Yu Zhang ${ }^{1,2^{*}}$, Uzair Aslam Bhatti ${ }^{1,2}$ and Qiong Chen ${ }^{1,2}$
}

\begin{abstract}
With deterioration of the global climate situation, the frequency and uncertainty of typhoons are the major causes of their hazards in tropical coastal regions, both in terms of loss of life and economic damage. Heavy rainfall triggers massive landslides and devastating flash floods, which can entail tremendous damage. In typhoon-affected areas, the key issue is to estimate the disaster zone and to help ships avoid disaster areas in the sea. Existing studies on typhoon disasters are mainly based on the overall wind assessment or the route prediction of the typhoon, with less attention to the detailed impact in different regions along the route. We propose in this paper a new framework to assess regional disaster risk based on chlorophyll-a concentration inversion in seawater. To calculate the concentration of chlorophyll-a, we analyze Landsat-8 satellite images in typhoon weather and normal weather in the same area. The experiments on realistic samples show that our approach has major potential to improve safety via assessing the impact of a typhoon in different regions based on the level of chlorophyll-a concentration.
\end{abstract}

Keywords: Typhoon hazards, Regional disaster risk, Chlorophyll-a concentration, Landsat-8 satellite images

\section{Introduction}

According to an analysis of 92 typhoons in the South China Sea during 1998-2009 by Yang and Tang [1], tropical depression is the main cause of typhoon generation at sea level. A cold vortex is characteristically present above the ocean environment during the period of a typhoon. Oceanic thermal structure is not stable because of the cold vortex. Therefore, cold water below a mixed layer is more likely to be brought to the upper layer of the sea [2]. Nutrients hidden in the deep ocean are brought to the upper level to cause phytoplankton bloom and to increase chlorophyll-a concentration [3, 4]. Other studies have shown that low chlorophyll-a concentration usually occurs in environments with low wind speed and high sea surface temperature, whereas high chlorophyll-a concentration occurs in environments with high wind speed and lower sea surface temperature $[5,6]$.

\footnotetext{
* Correspondence: huangmx09@163.com; yuzhang_nwpu@163.com ${ }^{1}$ State Key Laboratory of Marine Resource Utilization in South China Sea, Haikou 570228, China

Full list of author information is available at the end of the article
}

An out-of-date method uses fixed-location buoys to understand typhoon behavior, and the spots' change of state can be easily recorded [7]. This method is not 100\% accurate and not applicable to large areas. Along with the development of advanced satellite remote sensing technology, using satellites to monitor and study typhoon disasters is more efficient and effective due to the large observation area, time and space synchronization, and continuity, etc. For example, He and Zhang [8] monitored the development route and landing area of tropical storm "Sepat" and typhoon "Fitow" using the Fengyun-3 satellite. Liu et al. [9] used Landsat-8 data, combined with a Hainan Island topographic index and a damage potential index to analyze the impact of typhoons on rubber tree plantations. These works, however, focus mainly on a prediction of the estimated degree of overall impact and lack an assessment of impact on different regions along the typhoon route. As a result, no warning can be issued as to any regional typhoon disaster.

By using satellite data, we propose a new strategy and method to analyze the concentration of chlorophyll-a in seawater, which is calculated by chlorophyll-a inversion operation with Landsat- 8 sensing data. According to the 
regular change of chlorophyll-a concentration in seawater during typhoon weather $[10,11]$, we propose a new typhoon disaster model named Chlorophyll-a Typhoon Model (CTM), based on the regression model correlating chlorophyll-a concentration growth rate with tropical cyclone intensity and moving speed, by Shao [12]. In particular, CTM has the following advantages: First, there is no need to measure wind speed directly on the sea surface. Instead, it assesses the impact of a typhoon by the change of chlorophyll-a concentration in seawater when the typhoon is approaching. Second, an assessment more precise than that of existing methods for rubber plantations, for example, can be performed in different regions. One major challenge is how to find a chlorophyll-a inversion method suitable for the South China Sea environment. The key is to obtain chlorophyll-a content consistent with the actual environment of the South China Sea. Therefore, by discussing the linear inversion model, the logarithmic inversion model and the polynomial inversion model, we get significantly better results for chlorophyll-a concentration in the South China Sea. A detailed comparison of these models is shown in Section 2.5. The main contribution of this paper includes:

- A strategy for alerts using a new typhoon disaster model, providing a hypothetical basis for typhoon disaster assessment by measuring the impact of chlorophyll-a variation in seawater.

- The findings from our deep dataset analysis can help to inspire further studies on the use of hydrological evidence in regions of typhoon weather for assessing regional disasters.

- Our research also helps ships avoid loss of life and property during the typhoon season.
The rest of this paper is organized as follows: Section 2 introduces three different chlorophyll-a inversion models: Typhoon Regression Model, Fujitais Empirical Formula, and the Balance Model of Four Forces of Typhoon. In Section 2.5, we introduce our model named Chlorophyll-a Typhoon Model (CTM). In Section 3, we discuss the implementation of our Chlorophyll-a Typhoon Model. In Section 4, we present our experiments and methods. We analyze and discuss results in Section 5. In Section 7, we summarize and point out limitations.

\section{Background}

\subsection{Chlorophyll-a inversion model}

The selection of a chlorophyll-a inversion formula is important for accurate measurement of chlorophyll-a concentration. The commonly used chlorophyll-a inversion models include linear model, logarithmic model, and polynomial model [13]. Due to different natural environments, different sea areas need the corresponding inversion model. In this study, we need to find a suitable chlorophyll-a inversion model through experimental discussions. The models we established and discussed are as follows:

$$
\text { ChLa }=a \times B+k
$$

where $C h L a$ is the concentration of chlorophyll-a, $B$ is the waveband we selected, and $a$ and $k$ are the coefficients.

$$
C h L a=a \times \ln (B)+k
$$

where $C h L a$ is the concentration of chlorophyll-a, $B$ is the waveband we selected with natural $\log$ from Eq. (1), and $a$ and $k$ are the coefficients.

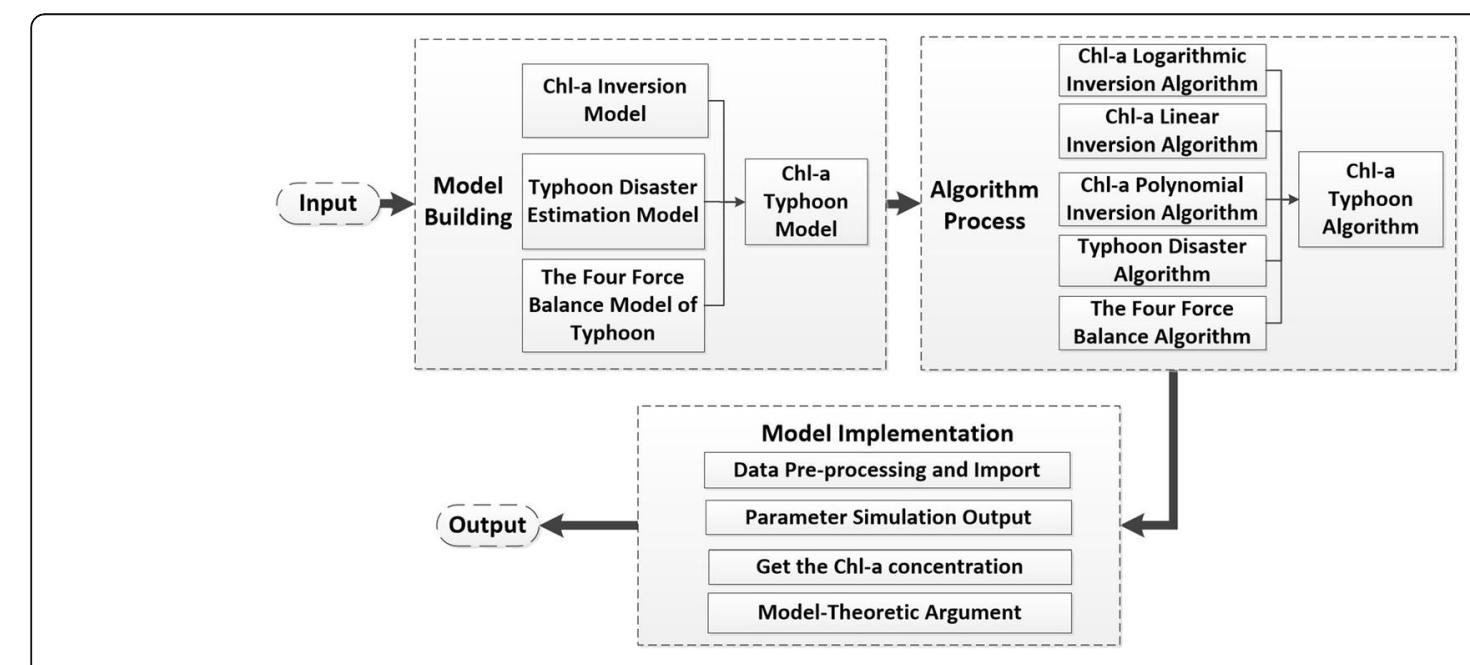

Fig. 1 The framework of typhoon disaster model CTM 


$$
\text { ChLa }=a \times B^{2}+b \times B+k
$$

where ChLa is the concentration of chlorophyll-a, $B$ is the waveband we selected, and $a, b$, and $k$ are the coefficients.

\subsection{Model for typhoon regression}

Many complex factors like atmospheric density, fictitious force, and wind speed impact the correlation between a typhoon and chlorophyll-a. It is more effective to set up the optimal combination with multiple independent variables to predict and estimate dependent variables than to use one independent variable.

The regression model is constructed with the chlorophyll-a concentration change rate, typhoon intensity, and typhoon speed, which come from the experiment with the data from the South China Sea by Shao [12].

$$
\text { Rate }=\beta_{0}+\beta_{1} S_{1}+\beta_{2} S_{2}+\varepsilon
$$

where Rate is the change rate of chlorophyll-a concentration between normal and typhoon weather; $S_{1}$ is the intensity of typhoon; $S_{2}$ is the speed of typhoon; $\beta_{0}, \beta_{1}$, and $\beta_{2}$ are the regression coefficients and estimated by data; and $\varepsilon$ is the random error.

\subsection{Fujitais empirical formula}

Many experiments have confirmed that the longitudinal distribution of typhoon's atmospheric pressure above sea surface can meet the requirements of Fujitais empirical formula [14]. Fujitais empirical formula is as follows:

$$
p_{(r)}=p_{E}-\Delta p\left[1+\left(\frac{r}{R}\right)^{2}\right]^{-0.5}
$$

$p_{(r)}$ is the atmospheric pressure of typhoon above sea surface; $p_{E}$ is the standard atmospheric pressure
Table 1 The information of the Landsat- 8 OLI data

\begin{tabular}{llll}
\hline \multicolumn{2}{l}{ Landsat-8 OLI } \\
$\begin{array}{llll}\text { Band } \\
\text { no. }\end{array}$ & Band name & $\begin{array}{l}\text { Wavelength/ } \\
\mathrm{nm}\end{array}$ & $\begin{array}{l}\text { Ground sample distance/ } \\
\mathrm{m}\end{array}$ \\
\hline 1 & New Deep Blue & $433-453$ & 30 \\
2 & Blue & $450-515$ & 30 \\
3 & Green & $525-600$ & 30 \\
4 & Red & $630-680$ & 30 \\
5 & NIR & $845-885$ & 30 \\
6 & SWIR2 & $1560-1660$ & 30 \\
7 & SWIR3 & $2100-2300$ & 30 \\
\hline
\end{tabular}

(generally $1000 \mathrm{hpa}$ ); $\Delta p$ is the intensity factor of typhoon, which also is the pressure difference between the environment and the center of typhoon; $R$ is the scale factor of typhoon; and $\left[1+\left(\frac{r}{R}\right)^{2}\right]^{-0.5}$ is used to standardize typhoon.

\subsection{The balance model of four forces of typhoon}

A typhoon is well-structured and strong because it is a complete weather system. It is a type of large storm system having a circular or spiral system of violent winds, typically hundreds of kilometers or miles in diameter; the structure of typhoon is clear and has a specific pathway and landing location. There are many factors that affect the movement of a typhoon such as pressure gradient, centrifugal force, Coriolis force, and friction force. The four forces balance to make ideal conditions, as follows:

$$
F_{p}+F_{c}+F_{C o}+F_{f}=0
$$

$F_{p}$ is due to the difference in horizontal pressure, and it pushes air particles from a high-pressure area to a low-pressure area, as follows:

\begin{tabular}{c|c|c|c}
\multicolumn{4}{c}{ Landsat-8 OLI } \\
\hline $\begin{array}{c}\text { Band } \\
\text { No. }\end{array}$ & $\begin{array}{c}\text { Band } \\
\text { Name }\end{array}$ & Wavelength/nm & $\begin{array}{c}\text { Ground Sample } \\
\text { Distance/m }\end{array}$ \\
\hline 1 & $\begin{array}{c}\text { New } \\
\text { Deep } \\
\text { Blue }\end{array}$ & $433-453$ & 30 \\
\hline 2 & Blue & $450-515$ & \\
\hline 3 & Green & $525-600$ & 30 \\
\hline 4 & Red & $630-680$ & 30 \\
\hline 5 & NIR & $845-885$ & 30 \\
\hline 6 & SWIR2 & $1560-1660$ & 30 \\
\hline 7 & SWIR3 & $2100-2300$ & 30
\end{tabular}

Fig. 2 The image of normal weather 


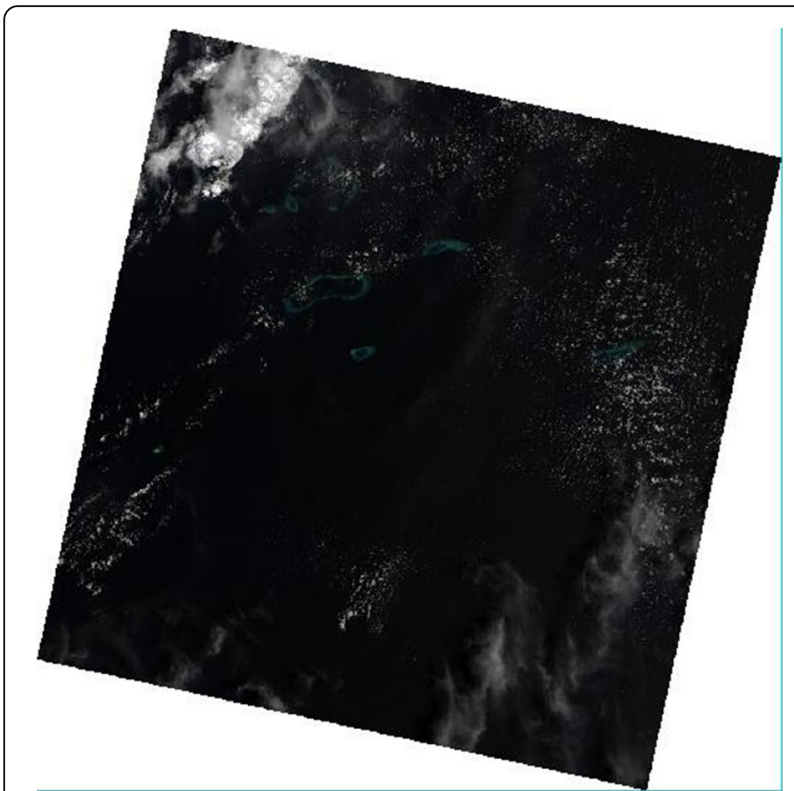

Fig. 3 The image of "Mujigae"

$$
F_{p}=\frac{\partial p}{\partial r}
$$

$P$ is the atmospheric pressure of the observed place; and $\Gamma$ is the distance from the observed place to a typhoon.

Since the circular motion in a typhoon-specific region is due to the inertia of an object, there is always a tendency for the object to fly along the tangential direction of the circle. This tendency is described as follows:

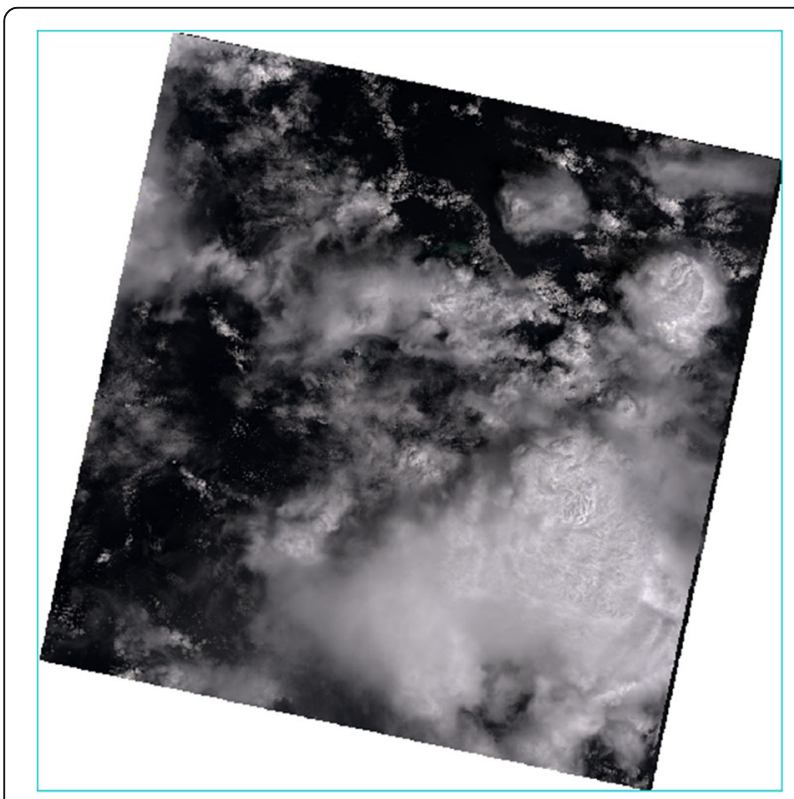

Fig. 4 The moving path of typhoon "Mujigae"

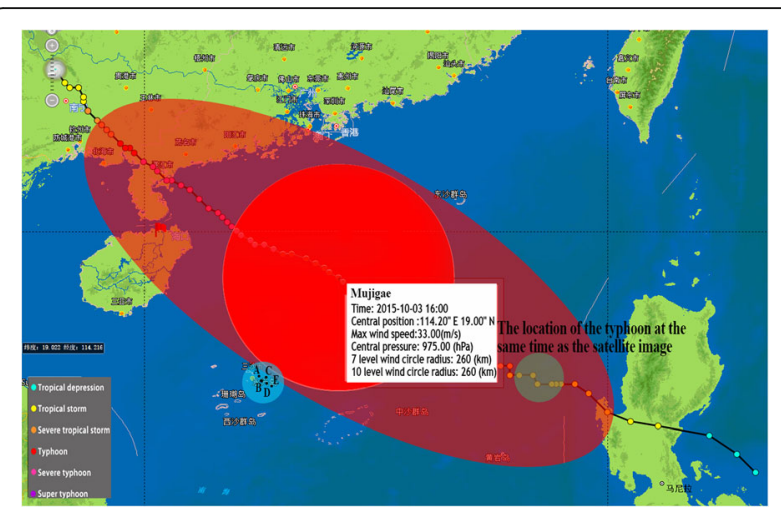

Fig. 5 The curve of spectrum of seawater before the atmospheric correction

$$
F_{c}=\rho \frac{v^{2}}{r}
$$

$\rho$ is the measure of atmospheric density in the region of a typhoon, and $v$ is the wind speed of the circumferential tangential direction.

The Coriolis force is a fictitious force used to explain a deflection in the path of a body moving in latitude relative to the earth when observed from earth. This force is described as follows:

$$
F_{C o}=\left\{\begin{array}{l}
-\rho f u,(\text { tangential Coriolis force }) \\
\rho f v,(\text { meridional Coriolis force })
\end{array}\right.
$$

$f$ is a constant determined by the selected region: $f=$ $2 \omega * \sin \phi ; \omega$ is the angular velocity of the earth's rotation; and $\phi$ is the dimension value of the selected area, which is positive in northern latitudes and negative in southern latitudes.

Rubbing action on the surface may result from the friction force of earth's surface, as follows:

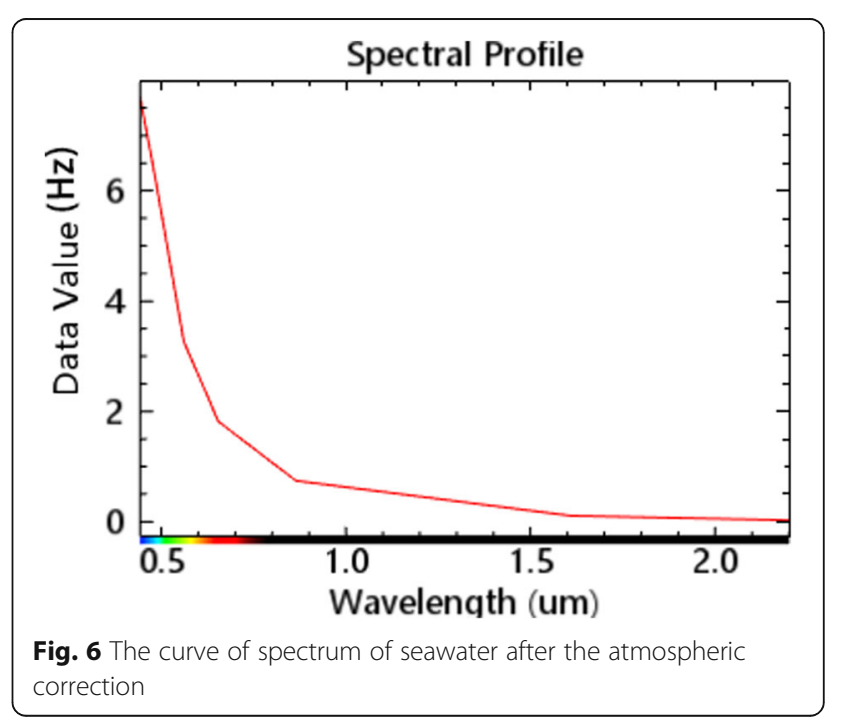




$$
F_{f}=\left\{\begin{array}{l}
\rho k h_{u} u,(\text { meridional friction force }) \\
\rho k h_{\nu} v,(\text { tangential friction force })
\end{array}\right.
$$

$k$ is the friction coefficient, and are the wind speeds, and $h_{u}$ and $h_{v}$ are the wind shear factors.

\subsection{Chlorophyll-a Typhoon Model}

Usually, the coefficient of friction $k$ is estimated by the undermined parameters. We make $h_{u} h_{v}=1$. Then, Eq. (4) can be changed as follows:

$$
\frac{v^{2}}{r}+f v-\frac{1}{\rho} \frac{\partial p}{\partial r}+\frac{1}{f} k^{2} v=0
$$

We make integration and induction operation between Eq. (3) and Eq. (11), as follows:

$$
f r v+v^{2}+f r v^{3}\left(\frac{k^{\prime \prime}}{f}\right)^{2}=\frac{\Delta p}{\rho} \frac{a^{2}-1}{a^{3}}, a=\sqrt{1+\left(\frac{r}{R}\right)^{2}}
$$

By using the measured data and data fitting method, we can find the parameters of the typhoon region. The scale factor of the typhoon and the friction factor are obtained in this way: the scale factor $R=21.9$ and the friction factor $k=3.7 \times 10^{-6}$. The parameters are taken into Eq. (12), and then, we get the typhoon wind speed equation as follows:

$$
v=\frac{1}{2}\left(-f r+\sqrt{(f r)^{2}+4 \frac{\Delta p}{\rho} \frac{a^{2}-1}{a^{3}}}\right)
$$

Equation (12) is modified and integrated with the Eq. (13) to obtain the wind power disaster model in the different regions of typhoon area based on the change rate of chlorophyll-a concentration. The Chlorophyll-a Typhoon Model (CTM) is described as follows:

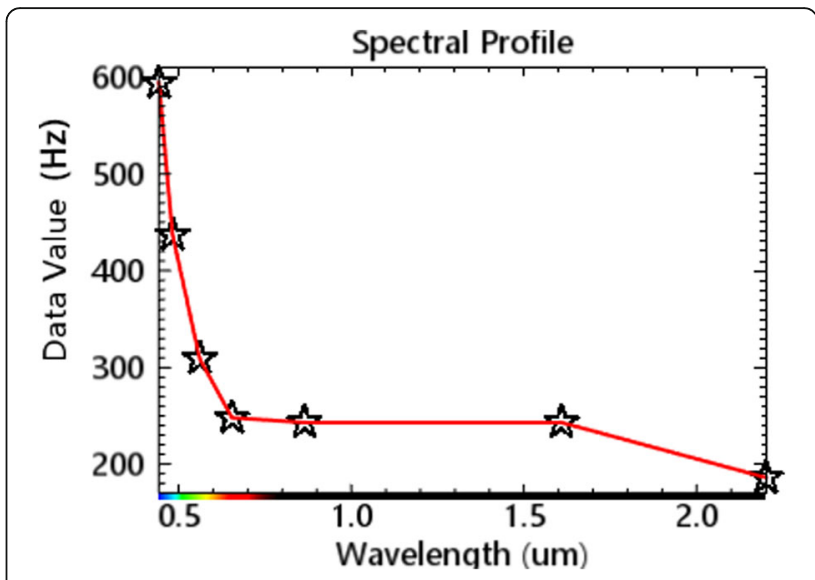

Fig. 7 Chlorophyll-a absorption spectrum curve

$$
S_{1}=\frac{\text { Rate }-\beta_{0}-\frac{1}{2} \beta_{2}\left(-f r+\sqrt{\left.(f r)^{2}+4 \frac{\Delta p}{\rho} \frac{a^{2}-1}{a^{3}}\right)}-\varepsilon\right.}{\beta_{1}}
$$

\section{The model implementation}

In order to build our new disaster model, we select and classify the original satellite data. Then, according to the typhoon path, we find the satellite data for the typhoon disaster area. Figure 1 is the framework of the data flow that we used to implement our Chlorophyll-a Typhoon Model. In the model building part, we reconstructed and innovated the existing models and developed our Chl-a Typhoon Model. In the algorithm progress part, we made our Chl-a Typhoon Model to be a concrete algorithm by utilizing the Chl-a Logarithmic Inversion Algorithm, Chl-a Linear Inversion Algorithm, Chl-a Polynomial Inversion Algorithm, Typhoon Disaster Algorithm, and Four Force Balance Algorithm. In the model implementation part, we conducted experiments on the filtered data by substituting

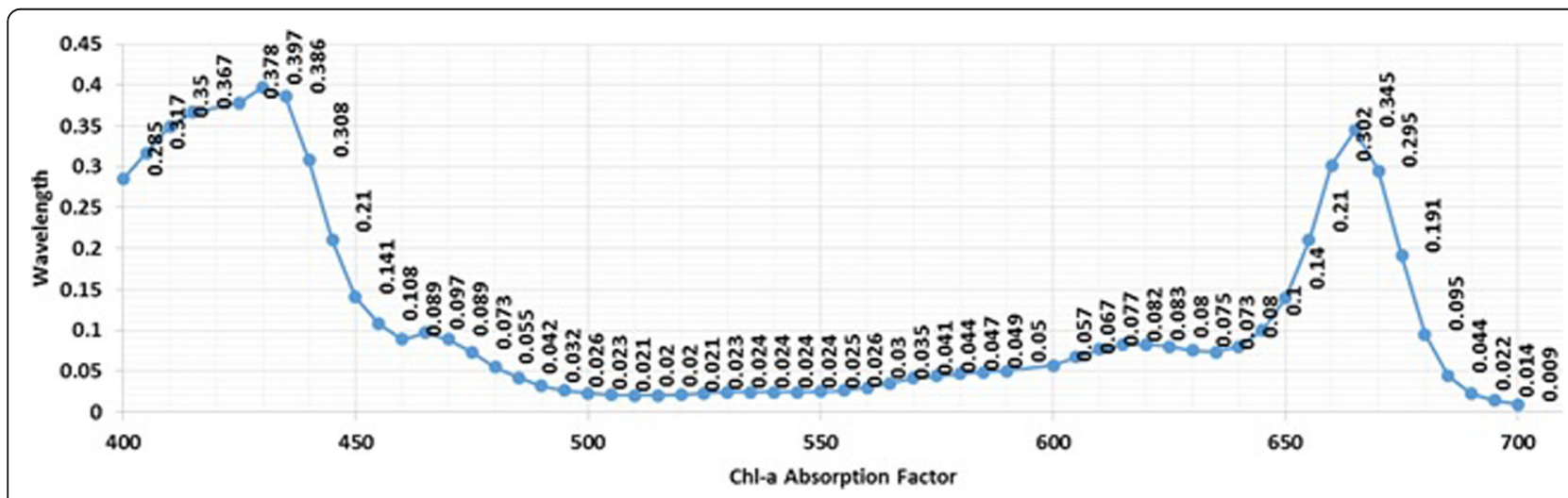

Fig. 8 Spectrum chart 
the data for the algorithm, and our discussion led to the results.

In this paper, the value of chlorophyll-a concentration in the study area's seawater is obtained by satellite data preprocessing and chlorophyll-a inversion, and the related experiments are based on the ENVI (v5.3) software platform by Esri. We used MATLAB Software to compute the correlation coefficient. The new disaster model is built by the combination of the correlation coefficient and the inversion result of chlorophyll-a concentration. Then, the model is applied to evaluate the impact in different regions of the typhoon area.

The framework makes the experimental process modular and reduces the repetition rate of the experimental procedure.

\section{Experiments and methods}

\subsection{Data}

The experimental data is from NASA Landsat-8 satellite, which mainly carries two different sensors: Operational Land Imager (OLI) and Thermal Infrared Sensor (TIRS) [15]. The data is in TIFF format, including the band's information, image files, the quality evaluation file, and the metadata of TXT format [15]. The quality evaluation file includes mainly the information of shooting time, solar elevation, and latitude and longitude of the satellite data.

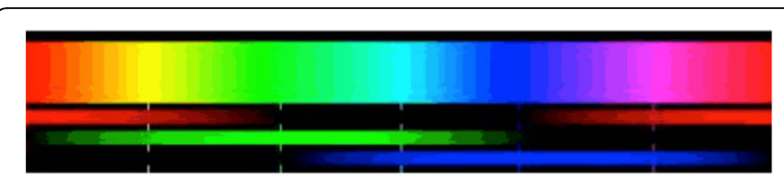

\begin{tabular}{|l|l|l|}
\hline Color & Frequency & Wavelength \\
\hline violet & $668-789 \mathrm{THz}$ & $380-450 \mathrm{~nm}$ \\
\hline blue & $631-668 \mathrm{THz}$ & $450-475 \mathrm{mn}$ \\
\hline cyan & $606-630 \mathrm{THz}$ & $476-495 \mathrm{~nm}$ \\
\hline green & $526-606 \mathrm{THz}$ & $495-570 \mathrm{~nm}$ \\
\hline yellow & $508-526 \mathrm{THz}$ & $570-590 \mathrm{~nm}$ \\
\hline orange & $484-508 \mathrm{THz}$ & $590-620 \mathrm{~nm}$ \\
\hline red & $400-484 \mathrm{THz}$ & $620-750 \mathrm{~nm}$ \\
\hline
\end{tabular}

Fig. 9 Correlation analysis between green light and red light

Landsat- 8 data can be used to study in different fields with different band combinations. Therefore, the Landsat- 8 data can be used to calculate the inversion of chlorophyll-a concentration in seawater. Therefore, in this paper, we used the Landsat- 8 OLI data to conduct the

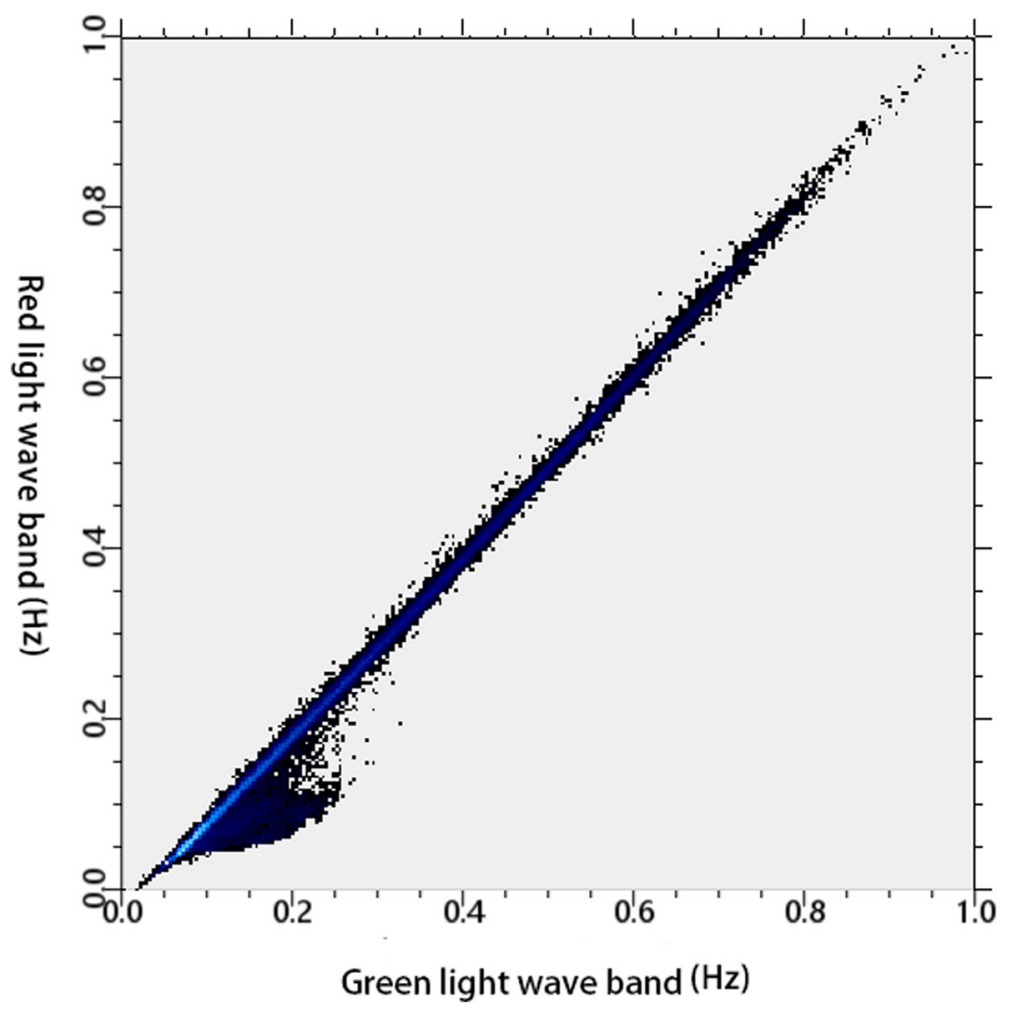

Fig. 11 The distribution of chlorophyll-a concentration in linear model 


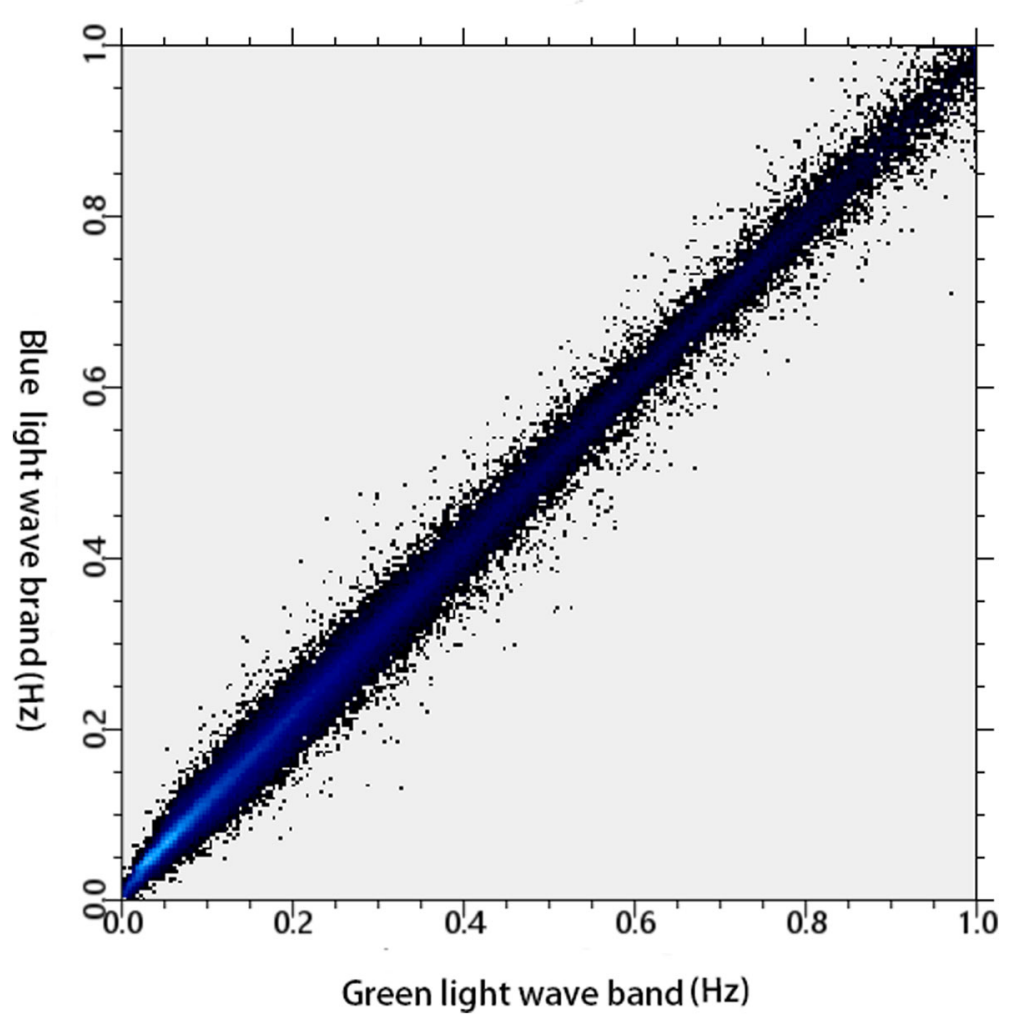

Fig. 10 Correlation analysis between green light and red light

experiment. Table 1 is the information of the Landsat- 8 OLI data. By means of radiometric calibration and atmospheric correction for Landsat- 8 satellite data, the effects of atmospheric interference, systematic noise, the posture of the sensor, and so on can be removed.

In this experiment, we selected two satellite images at different times in the same location. The central dimension $\left(\mathrm{N} 15.9^{\circ} ; \mathrm{E} 111.9^{\circ}\right)$ of the satellite images is the same. Figure 2 is the satellite image on August 31, 2015, when the weather was normal. Figure 3 is the satellite image on October 2, 2015, when the typhoon "Mujigae" was approaching.

We obtained the information about "Mujigae" from the South China Sea typhoon network.

\subsection{Study area}

In current research, a typhoon will cause precipitation over a large area. The precipitation over coastal land will push phytoplankton and soluble organic matter into

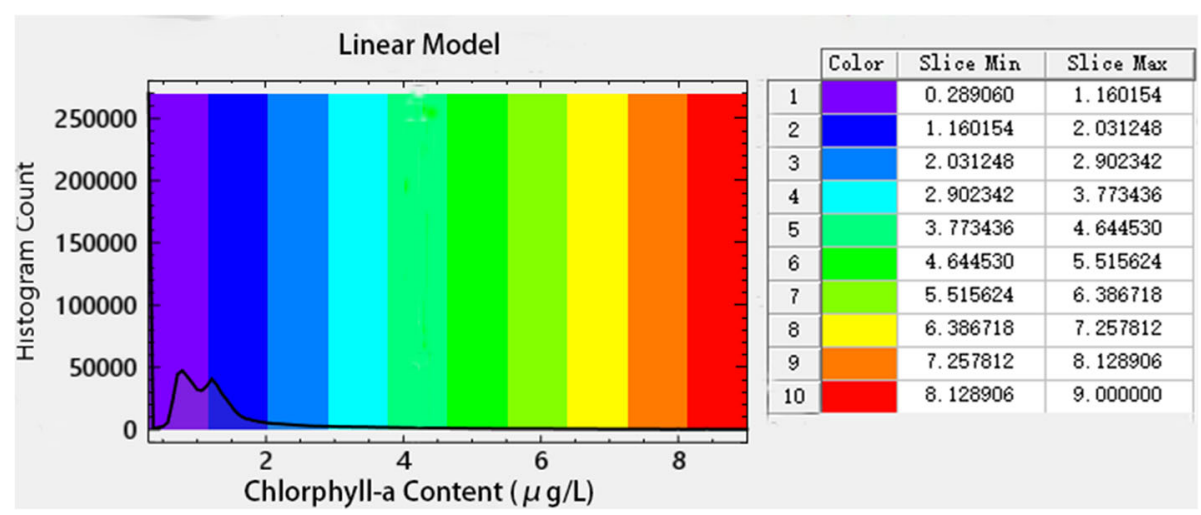

Fig. 12 The distribution of chlorophyll-a concentration in logarithmic model 


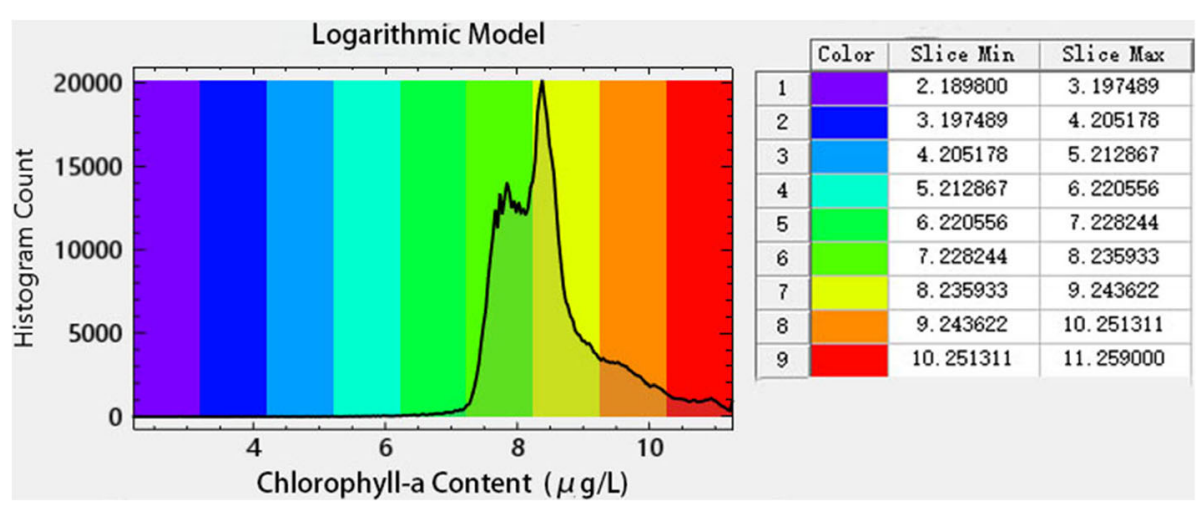

Fig. 13 The distribution of chlorophyll-a concentration in polynomial model

coastal seawater, which will cause an increase of chlorophyll-a concentration in coastal seawater [16]. At the same time, with population increase and development of industry and agriculture in recent years, the eutrophication of coastal seawater has been aggravated [17]. The above interference factors will affect the experimental results. Therefore, in this study, we chose a study area near Xisha Island because of fewer interference factors. Figure 4 is the detailed assessment area selected according to the route of typhoon "Mujigae."

In Fig. 4, the longitude and latitude of the study area are $\mathrm{E} 111.9^{\circ}$ and $\mathrm{N} 15.9^{\circ}$, respectively. We selected point $\mathrm{A}$ $\left(\mathrm{N} 16.572^{\circ} ; \mathrm{E} 112.154^{\circ}\right)$, point B (N16.570 $\left.; \mathrm{E} 112.162^{\circ}\right)$, point $\mathrm{C}\left(\mathrm{N} 16.449^{\circ} ; \mathrm{E} 112.612^{\circ}\right)$, point $\mathrm{D}\left(\mathrm{N} 16.395^{\circ}\right.$; E113.903 ${ }^{\circ}$, and point E $\left(\mathrm{N} 16.387^{\circ}\right.$; E112.915 $)$ as sample points in the study area.

In Fig. 4, the time of the satellite image of the study area is 11 am Beijing time on October 2, 2015. At the same time, the position of typhoon "Mujigae" is shown as the small gray circle. The latitude and longitude of the small gray circle are $\mathrm{N} 16.713^{\circ}$ and $\mathrm{E} 119.3^{\circ}$, respectively. As typhoon "Mujigae" continued to move, we determined the typhoon's position nearest to the study area through the typhoon's path to be the biggest circle (the latitude is $\mathrm{N} 19.003^{\circ}$ and the longitude is E114.201 ${ }^{\circ}$ ) in Fig. 4. The time of the biggest circle is $4 \mathrm{pm}$ Beijing time on October 3, 2015.

\subsection{Experimental environment and method}

We did satellite inversion to obtain chlorophyll-a concentration in seawater of the study area through the latest software platform. Figure 5 is the curve of seawater spectrum before atmospheric correction. Figure 6 is the curve of seawater spectrum after atmospheric correction. By comparing Fig. 5 with Fig. 6, we find that after the atmospheric correction, the satellite images reflect the real situation of solar radiation.

The imagining, coding, and mathematical analysis of the research are carried out in MATLAB because of our expertise and robust features of its software. The correlation coefficient of the new typhoon disaster model is obtained after a binary linear regression analysis.

Experimental procedure is explained step by step as follows:

- Obtained the typhoon level "L" of different sample points: La, Lb, Lc, Ld, and Le.

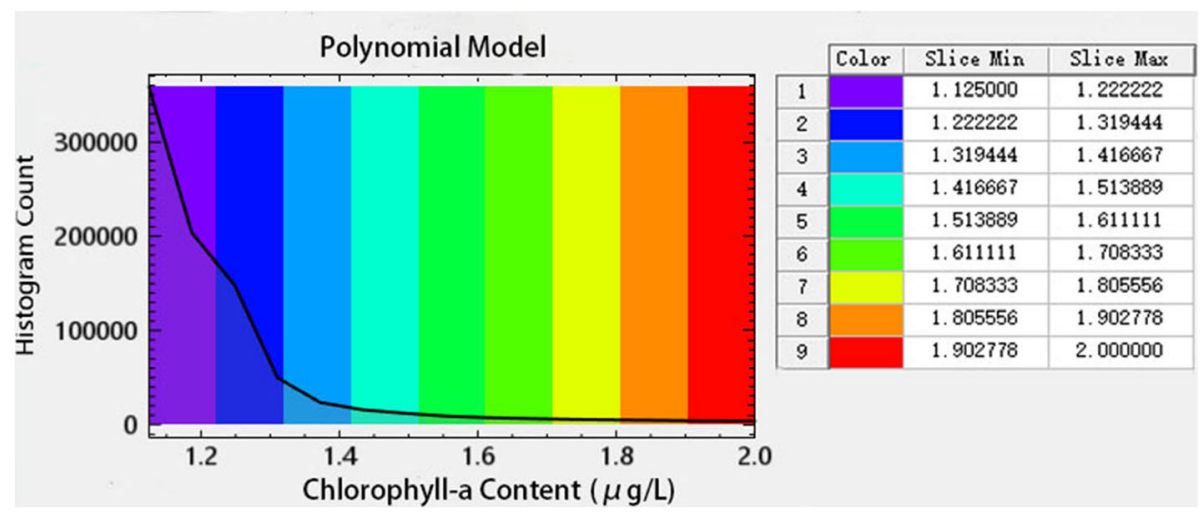

Fig. $14 \mathrm{Chl}-\mathrm{a}$ value and wind speed value of sample 
Table 2 National standards for tropical cyclones in China

\begin{tabular}{lll}
\hline Grade of tropical cyclones & $\begin{array}{l}\text { The maximum average wind speed near the } \\
\text { center of the bottom }\left(\mathrm{m} \times \mathrm{s}^{-1}\right)\end{array}$ & $\begin{array}{l}\text { The maximum wind near the center } \\
\text { of the bottom (level) }\end{array}$ \\
\hline Tropical depression & $10.8 \sim 17.1$ & $6 \sim 7$ \\
Tropical storm & $17.2 \sim 24.4$ & $8 \sim 9$ \\
Severe tropical storm & $24.5 \sim 32.6$ & $10 \sim 11$ \\
Typhoon & $32.7 \sim 41.4$ & $12 \sim 13$ \\
Severe typhoon & $41.5 \sim 50.9$ & $14 \sim 15$ \\
Super typhoon & $\geq 51.0$ & 16 or above
\end{tabular}

- Used the chlorophyll-a inversion operation for measuring the chlorophyll-a concentration "CHL-a": CHL-aA, CHL-aB, CHL-aC, CHL-aD, and CHL-aE.

- The relevant parameters of the sample points were brought into Eq. (14) Chlorophyll-a Typhoon Model (CTM) to obtain the calculated value "S" of the typhoon's wind intensity: SA, SB, SC, SD, and SE.

- We made the histogram of the typhoon level "L," the histogram of the chlorophyll-a concentration "CHLa," and the curve of the wind assessment value " $\mathrm{S}$ " respectively. According to a comparison of the different tendencies of these three graphs, we determined it is possible to assess the potential of typhoon disaster in advance by studying the chlorophyll-a concentration of different sample points in seawater when the typhoon is approaching.

\section{Results and discussion}

\section{Chlorophyll-a concentration}

The phytoplankton in the South China Sea is dominated by dinoflagellates and diatoms [18]. By studying algae in different water bodies, Zhao and others found that the spectral signature of the curve of the spectrum are common to water bodies, and at the same time, due to the low absorption of algae, there is a wide range of maximum reflectance near the wavelength of $560 \mathrm{~nm}$ [19]. The absorption rate curve of chlorophyll-a is drawn by measuring datum, and Fig. 7 is obtained.
In Fig. 7 , we can find that the absorbance rate of chlorophyll-a is the lowest in the range of $500 \mathrm{~nm}$ to $560 \mathrm{~nm}$, which means the reflectance is highest in this region. Figure 8 is the spectrum chart. By comparing Figs. 7 and 8 , we find that the highest reflectivity region belongs to the green band [20,21].

By observing the chlorophyll-a absorption spectrum curve in Fig. 7 and the spectrum chart in Fig. 8, we find that it also has a low absorption rate in the range of 450 to $475 \mathrm{~nm}$ and the range of 620 to $650 \mathrm{~nm}$, which belong to the blue and red bands, respectively. We analyzed the correlation of the green band with the red and blue bands, respectively, then drew the curve and arrived at Figs. 9 and 10. Through a correlation comparison, we found that in Fig. 9, there is not too much difference between the green and blue bands; in Fig. 10, the green and red bands are consistent in most areas. Finally, through correlation comparison and the chlorophyll-a absorption spectrum curve, we chose to use the green band to do the inversion operation of chlorophyll-a content.

The inversion of chlorophyll-a content was carried out according to the formulas of Chl-a Linear Inversion Algorithm, Chl-a Logarithmic Inversion Algorithm, and Chl-a Polynomial Inversion Algorithm. Figures 11, 12, and 13 show the distribution of chlorophyll-a concentration in the study area. According to the distribution histograms, we find that the concentration of chlorophyll-a is mainly concentrated in $0-9(\mu \mathrm{g} / \mathrm{L})$ and is in a reasonable range [22].

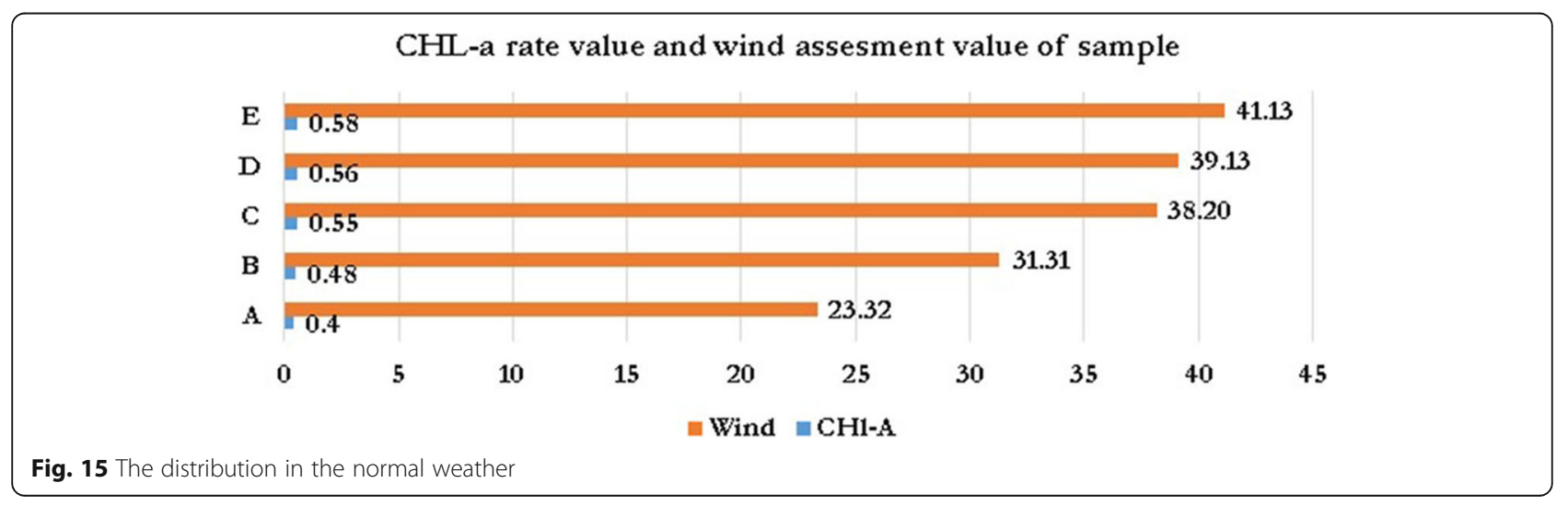




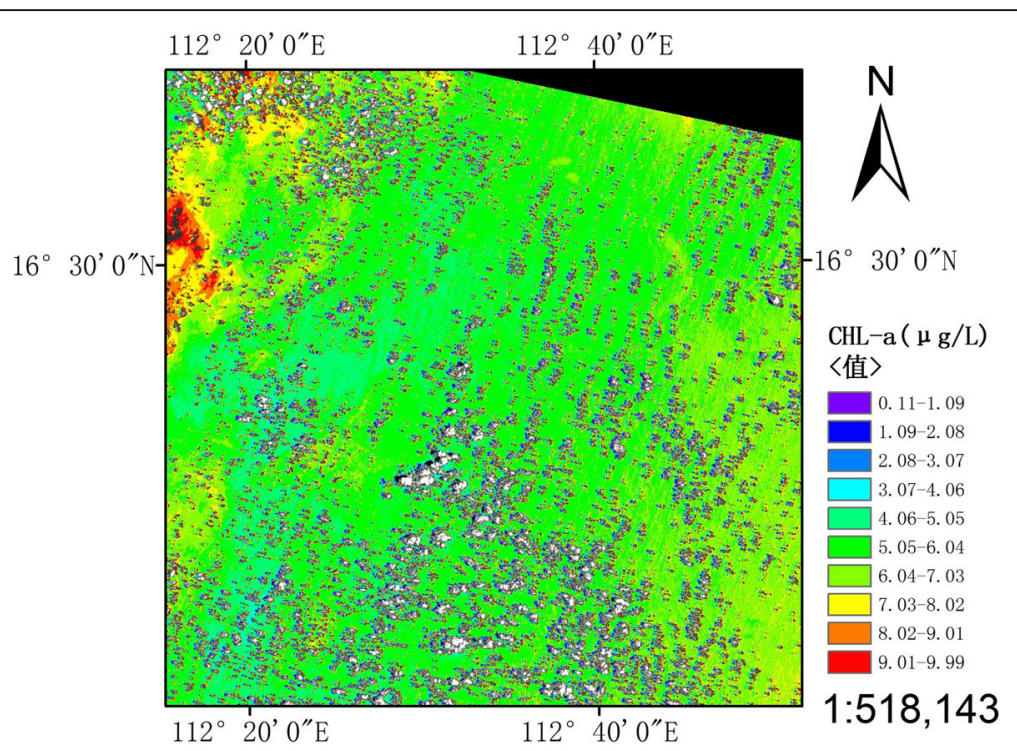

Fig. 16 The distribution in typhoon "Mujigae"

Che and Ran studied the distribution of chlorophyll-a concentration in the South China Sea in summer and found Chl-a content varied from below detection to 0.51 $(\mu \mathrm{g} / \mathrm{L})$ with an average of $0.10 \pm 0.09(\mu \mathrm{g} / \mathrm{L})$ and decreases gradually with depth below $50 \mathrm{~m}$, reaching zero at a depth of $200 \mathrm{~m}$ [23]. So by comparing Figs. 11, 12 and 13, we find that chlorophyll-a concentration in Fig. 11 is closer to real values. So, we chose the chlorophyll-a concentration from Fig. 11 to be the experimental datum of the Chlorophyll-a Typhoon Model.

Then, we obtain the concentration of chlorophyll-a at sample points A, B, C, D, and E. As shown in Fig. 14, the value of point $A$ is $5(\mu \mathrm{g} / \mathrm{L})$, the value of point $B$ is 5 $(\mu \mathrm{g} / \mathrm{L})$, the value of point $\mathrm{C}$ is $6(\mu \mathrm{g} / \mathrm{L})$, the value of point $D$ is $8(\mu \mathrm{g} / \mathrm{L})$, and the value of point $E$ is $8(\mu \mathrm{g} / \mathrm{L})$.

\subsection{Typhoon wind speed}

We obtained the correlation coefficient of CTM by linear regression analysis. Then, the correlation coefficient and the change rate of chlorophyll-a concentration at the sample points are brought into CTM. In this way, we obtained the calculated value " $\mathrm{S}$ " of the wind assessment value at the sample points. As shown in Fig. 14, the value of $\mathrm{SA}$ is $23.32(\mathrm{~m} / \mathrm{s})$, the value of $\mathrm{SB}$ is

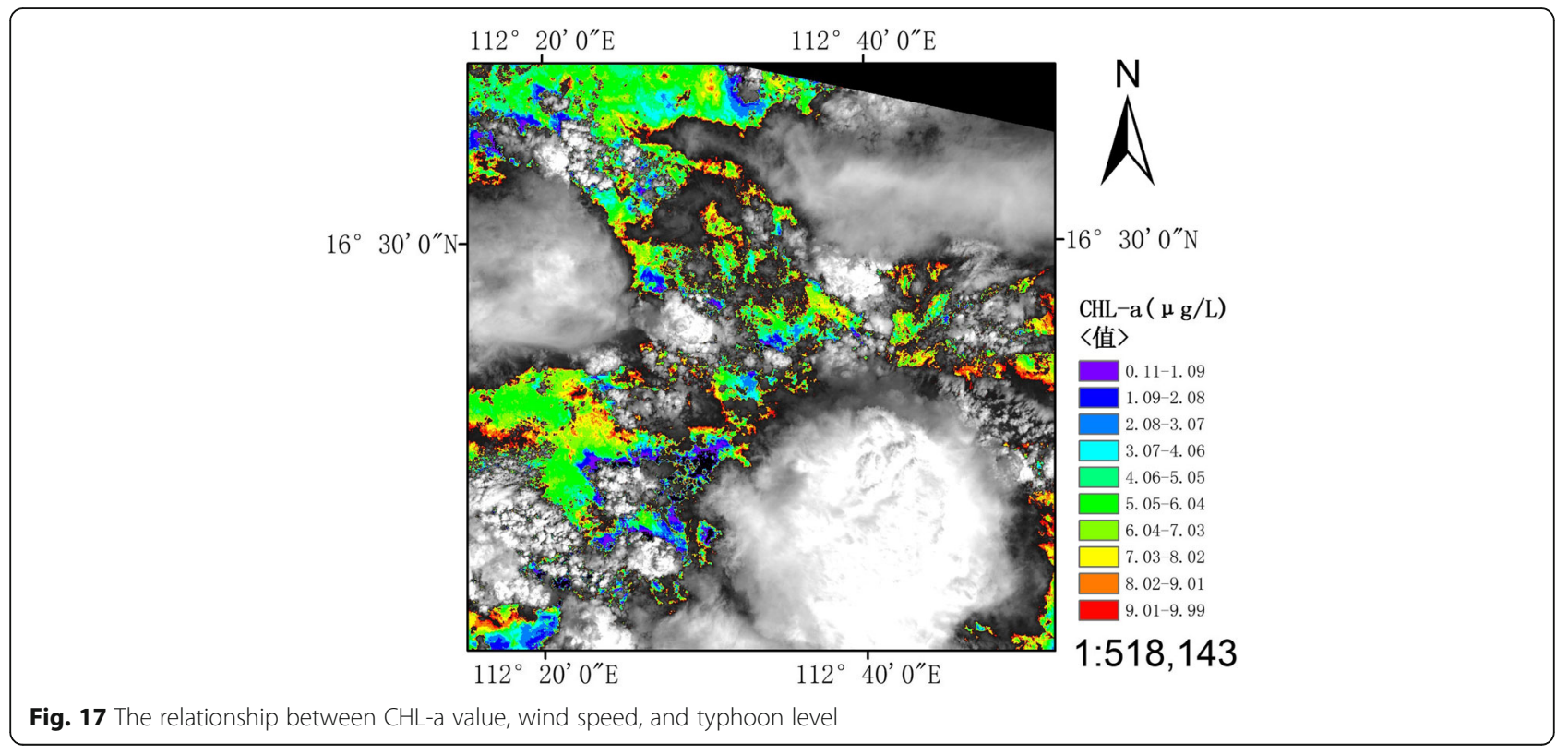


$31.31(\mathrm{~m} / \mathrm{s})$, the value of $\mathrm{SC}$ is $38.20(\mathrm{~m} / \mathrm{s})$, the value of $\mathrm{SD}$ is $39.13(\mathrm{~m} / \mathrm{s})$, and the value of SE is $41.13(\mathrm{~m} / \mathrm{s})$. The wind speed assessment values at sample points are in line with the national standards for tropical cyclones in China, as shown in Table 2.

\subsection{The discussion between chlorophyll-a concentration and the wind power value}

Figure 15 shows the distribution of chlorophyll-a concentration in the seawater of the study area during normal weather by satellite inversion on August 31, 2015. From Fig. 15, we can see that during normal weather, the distribution of chlorophyll-a is even, and the concentration of chlorophyll-a is mainly concentrated around 4 $(\mu \mathrm{g} / \mathrm{L})$.

Figure 16 shows the distribution of chlorophyll-a concentration in the seawater of the study area during typhoon weather by satellite inversion on October 2, 2015, when typhoon "Mujigae" was approaching.

In Fig. 16 the white part of the image is the cloud area caused by typhoon "Mujigae." The distribution of chlorophyll-a concentration appears irregular when typhoon "Mujigae" was approaching. We see chlorophyll-a concentration in seawater of the study area is in 0.119.99 $(\mu \mathrm{g} / \mathrm{L})$, and the highest chlorophyll-a concentration is $9.99(\mu \mathrm{g} / \mathrm{L})$. The place of the highest concentration is near the area of the blast ring of typhoon "Mujigae." The concentration of chlorophyll-a in the remaining area is different as determined by the wind power of typhoon "Mujigae."

By comparing Figs. 15 and 16, we draw the following conclusions:

- Concentration of chlorophyll-a in the seawater changes upon the arrival of the typhoon. The figures clearly demonstrate that the concentration of chlorophyll-a is not unique.

- There is a correlation between the concentration of chlorophyll-a in seawater and the wind power of a typhoon.

- Higher strength of wind means higher chlorophyll-a concentration in the same area.

As shown in Fig. 17, we compared the relationship among chlorophyll-a concentration value, wind assessment value, and typhoon level of "Mujigea" at the sample points.

From Fig. 17, we see that the variations of chlorophyll-a concentration, the wind assessment value, and the wind level of typhoon "Mujigea" at the sample points tend to be the same.

From the above experimental analysis, we draw the conclusion that at the time of the typhoon the change of the chlorophyll-a content in seawater can be used to estimate the typhoon's wind force in that specific area. The content of chlorophyll-a in different regions of the seawater indicates that the wind force is different in different regions. When the content of chlorophyll-a in seawater is higher, the wind force is stronger. The aforementioned experimental results ensure that our new proposed typhoon disaster model (14) is feasible and effective for the prediction of typhoon disaster. The model also provides a new approach to study regional typhoon disaster. With help from the data on chlorophyll-a concentration in seawater of the typhoon disaster area, ships can choose a safe alternate route to avoid loss caused by typhoon disaster.

\section{Conclusion}

In our study and research in this paper, we present a strategy for alerts using a new typhoon disaster model, forming a hypothetical basis for typhoon disaster assessment according to the impact of chlorophyll-a variation in seawater. Our study provides a deep dataset analysis and helps elaborate a new idea, inspiring further studies on the use of hydrological evidence in typhoon weather to assess regional disaster. Moreover, our research also helps ships avoid life and property loss during typhoon weather. Though the current solution still has limits, our research is creative and innovative, and the model could be improved in the future:

- The Landsat-8 satellite data selected in this paper is susceptible to cloud interference. It is suggested that microwave remote sensing satellite data be used, such as the satellite data of GF-3, which has been launched in China. If conditions permit, we recommend using a combination of the chlorophyll-a concentration value obtained from a buoy in seawater and the satellite inversion method. In this way, the accuracy of chlorophyll-a concentration in seawater during typhoon weather can be improved.

- The data discontinuity in time leads to imprecise results and an inaccurate qualitative analysis.

- Further study should be carried out in different regions of the Pacific Ocean utilizing wireless sensor networks (WSN) [24, 25], as we focused in this research only on the South China Sea.

Abbreviations

CTM: Chlorophyll-a Typhoon Model; OLI: Operational Land Imager

\section{Acknowledgements}

Special thanks to Mengxing Huang for giving us time and support in all stages of research so that we could achieve our targets.

\section{Funding}

This research is supported by the National Natural Science Foundation of China (Grant no. 61462022), the National Key Technology Support Program (Grant no. 2015BAH55F04 and Grant no. 2015BAH55F01), Major Science and Technology Project of Hainan province (Grant no. ZDKJ2016015), Natural 
Science Foundation of Hainan province (Grant no. 614232 and Grant no. 617062), and Scientific Research Staring Foundation of Hainan University (Grant no. kyqd1610).

\section{Availability of data and materials}

Live data have been taken from software and uploaded in the section of figures.

\section{Authors' contributions}

All authors contributed equally to this paper in all parts of the writing such as design, presentation, analysis, and results interpretation. All authors read and approved the final manuscript.

\section{Authors' information}

Di Wu (1991-), Hainan University, Master student, Main Research Areas: Big Marine Data, Remote Sensors, Al and Robotics

Mengxing Huang (1973-), China, Hainan University, Professor, Doctoral Supervisor, Main Research Areas: Big data and smart services Yu Zhang (1983-), China, Hainan University, Doctor, Main Research Areas: The collaborative design and validation of embedded system Uzair Aslam Bhatti (1986-), Hainan University, Phd student, Main Research Areas: Big Data, Artificial Intelligence and Health Informatics.

\section{Competing interests}

The authors declare that they have no competing interests.

\section{Publisher's Note}

Springer Nature remains neutral with regard to jurisdictional claims in published maps and institutional affiliations.

\section{Author details}

'State Key Laboratory of Marine Resource Utilization in South China Sea, Haikou 570228, China. ${ }^{2}$ College of Information Science and Technology, Hainan University, Haikou 570228, China.

Received: 6 November 2017 Accepted: 12 November 2018

Published online: 20 December 2018

\section{References}

1. Y. Xiao-xia, T. Dan-ling, Location of sea surface temperature cooling induced by typhoon in South China Sea. J. Trop. Oceanogr. 29(4), 26-31 (2010)

2. Y.L.L. Chen, Spatial and seasonal variations of nitrate. Deep-Sea Res. Oceanogr. Res. Pap. 52(2), 319-340 (2005)

3. L. Zhou, Y. Tan, L. Huang, et al., Phytoplankton growth and microzooplankton grazing in the continental shelf area of northeastern South China Sea after typhoon Fengshen. Cont. Shelf Res. 31(16), 1663$1671(2011)$

4. X. Lu, K. Ota, M. Dong, C. Yu, H. Jin, Predicting transportation carbon emission with urban big data. T-SUSC 2(4), 333-344 (2017)

5. X. Wang, X. Xing, et al., A satellite-based analysis on the seasonal variations and inter-relationships between chlorophyll and particle in the South China Sea. Acta Oceanol. Sin. 37(10), 26-38 (2016)

6. L.R. Lin, H. Zhao, Analysis on the relations between sea surface temperature and phytoplankton chlorophyll-a in the South China Sea. J. Mar. Sci. 4(30), 46-54 (2012)

7. D.J. Doong, L.Z.H. Chuang, C.C. Kao, Y.B. Lin, K.C. Jao, Statistics ofbuoyobserved waves during typhoons at Taiwanese waters from 1997 to 2008. In OCEANS 2009, MTS/IEEE Biloxi-Marine Technology for Our Future: Global and Local Challenges (pp. 1-7). IEEE. (2009)

8. J. He, S. Zhang, Introduction of MWHTS onboard FY-3C Satellite and Typhoon Detecting. Remote Sens. Sci. 2, 17-24 (2015)

9. C. Bangqian, X. Li, X. Xiao, B. Zhao, J. Dong, K. Kou, Y. Qin, "Mapping tropical forests and deciduous rubber plantations in Hainan Island, China by integrating PALSAR 25-m and multi-temporal Landsat images." International journal of applied earth observation and geoinformation 50, 117-130 (2016).

10. X. Liu, M. Wang, W. Shi, A study of a hurricane Katrina-induced phytoplankton bloom using satellite observations and model simulations. J. Geophys. Res. Oceans 114(C3), 819-834 (2009)

11. I.-I. Lin, Typhoon-induced phytoplankton blooms and primary productivity increase in the western North Pacific subtropical ocean. J. Geophys. Res. Oceans 117(117), 3039 (2012)
12. D.I. Wu, H. Mengxing, U.A. Bhatti, Z. Li, H. Zhang. "Typhoon early warning modeling for regional disaster evaluation." In Enterprise Systems (ES), 2017 5th International Conferenceon, pp. 26-29. IEEE, 2017.

13. Y. Pan, D. Tang, D. Weng, Evaluation of the SeaWiFS and MODIS chlorophyll a algorithms used for the Northern South China Sea during the summer season. Terr. Atmos. Ocean. Sci. 21(6), 997-1005 (2010)

14. Z.B.C.Y.S. Guangwu, Statistical Analysis of Tropical Cyclones Affecting East China Sea in Recent 45 Years [J]. Meteorological Science and Technology, 5, p.010 (2009).

15. Z. Yujun, Landsat8 abstract. Remote Sens. Land. Resour. 25(1), 176-177 (2013)

16. T. Davergne, Offshore and nearshore chlorophyll increases induced by typhoon winds and subsequent terrestrial rainwater runoff. Mar. Ecol. Prog. 333(1), 61-74 (2007)

17. L. Zhao, S. Shuqun, L. Caiwen, Distribution of chlorophyll-a and its correlation with the formation of hypoxia in the Changjiang River Estuary and its adjacent waters. Mar. Sci. 40(2), 1-10 (2016)

18. T.Y. Ho, X. Pan, H.H. Yang, et al., Controls on temporal and spatial variations of phytoplankton pigment distribution in the Northern South China Sea. Deep-Sea Res. II Top. Stud. Oceanogr. 117(6), 65-85 (2015)

19. D.Z. Zhao, F.S. Zhang, D.U. Fei, et al., Interpretation of sun-induced fluorescence peak of chlorophyll a on reflectance spectrum of algal waters. J. Remote. Sens. 9(3), 265-270 (2005)

20. G. Nofuentes, B. García-Domingo, J.V. Muñoz, et al., Analysis of the dependence of the spectral factor of some PV technologies on the solar spectrum distribution. Appl. Energy 113(2), 302-309 (2014)

21. B. Yang, J. Chen, L. Chen, et al., Estimation model of wheat canopy nitrogen content based on sensitive bands. Trans. Chin. Soc. Agric. Eng. 31(22), 176$182(2015)$

22. C. Qiong, M. Huang, H. Wang, Y. Zhang, W. Feng, X. Wang, D.I. WU, U.A. Bhatti, "A Feature Preprocessing Framework of Remote Sensing Image for Marine Targets Recognition." In 2018 OCEANS-MTS/IEEE Kobe TechnoOceans (OTO), pp. 1-5. IEEE, (2018)

23. C. Hong, R.X. Bin, Distributions of three size fractions of chlorophyll-a and its controlling factors in summer in the southern South China Sea. J. Hydroecol. 33(4), 63-72 (2012)

24. H.-N. Dai, R.C.-W. Wong, H. Wang, On capacity and delay of multi-channel wireless networks with infrastructure support. IEEE Trans. Veh. Technol. 66(2), 1589-1604 (2017)

25. Y. Wu, G. Min, L.T. Yang, Performance analysis of hybrid wireless networks under Bursty and correlated traffic. IEEE Trans. Veh. Technol. 62(1), 449-454 (2013)

\section{Submit your manuscript to a SpringerOpen ${ }^{\circ}$ journal and benefit from:}

- Convenient online submission

Rigorous peer review

- Open access: articles freely available online

High visibility within the field

- Retaining the copyright to your article

Submit your next manuscript at $\boldsymbol{\nabla}$ springeropen.com 